\title{
Optimization of sensors locations in internal stability analysis of Geosynthetic-reinforced earth retaining walls
}

\author{
Hicham Alhajj Chehade ${ }^{1,2}$, Marwan Sadek ${ }^{2}$, Daniel Dias ${ }^{3,4}$, Fadi Hage Chehade ${ }^{2}$, Orianne \\ Jenck $^{1}$ \\ 1 Laboratoire Sols, Solides, Structures, Risques, Université Grenoble-Alpes, 38000 Grenoble, France \\ 2 Laboratoire Centre de Modélisation, Université Libanaise, Beyrouth, Liban \\ 3 Université de technologie de Hefei, Hefei, China \\ 4 Antea Group, Antony, France
}

\begin{abstract}
This paper concerns the optimization of sensors locations used to monitor the geosynthetic reinforcement internal forces of a reinforced earth retaining walls. The internal stability analysis of these structures is addressed through the kinematic theorem of limit analysis combined with the discretization technique to generate the failure surface. Knowing that the majority of damages of these structures are caused by the water presence in the reinforced zone, different water table levels are considered in the study and their effects on the critical failure surface location are analyzed.
\end{abstract}

\section{Geotechnical structures risks}

\subsection{Geosynthetic reinforced earth retaining walls}

Geosynthetic reinforced earth retaining walls is a construction technique based on the association of compacted backfill soil and geosynthetic reinforcement (straps, geogrids or geotextiles) connected to a facing (Figure 1). The structure behaves like a coherent flexible block, capable of supporting important loads thanks to the soil-reinforcement interaction.

The reinforced earth technique constitutes one of the most important development in civil engineering in the last five decades. This success is explained by the advantages offered by this technique compared to their conventional counterparts concerning money, time and space saving. These advantages have led to a wide use of this technique in many fields of Civil Engineering. It is used in the transportation construction in the roads, highways, bridges and railway structures, as well as for industrial and protective structures, dams, mining structures, in addition to its use for commercial and public structures. The multiple fields where reinforced earth retaining walls are used, show the importance of these structures in any urban development especially in areas with challenging design conditions.

\subsection{Vulnerability of the reinforced earth walls}

The reinforced earth walls suffer from vulnerability to natural hazards such as earthquakes and rainfalls. Safety constitutes the great challenge of this space. The vital role of 
geosynthetic reinforced earth walls, explained by their multiple applications, shows the importance of their management and monitoring. The failures of these structures could lead to huge human and economic losses. Many challenging issues have to be addressed when dealing with these structures such as very large structural loads, water presence, crackformation in the backfill and seismic loading.

\subsection{Rainfall hazard}

In most important design codes (e.g. FHWA-NHI-11-024, NF P 94-270), a cohesionless soil is recommended and considered with an appropriate drainage system. These recommendations aim to ensure a fast removal of excess water from the soil. Then, the stability assessment of reinforced earth walls is conducted assuming the absence of pore water pressure in the backfill. However, most failures encountered in the literature were caused by the water presence in the backfill when a cohesive soil is used. Koerner and Koerner [1] presented in their paper the cases of 320 reinforced earth walls failures. Most of these failures are caused by internal or external water (201 cases or $63 \%$ ), and in 232 cases $(73 \%)$ a cohesive soil (Silt or clay) is used as backfill in the reinforced zone. This statistic study proved that the design codes specifications and recommendations are not respected in a lot of times. In fact, the circumstances sometimes lead to the use of poorly cohesive soils in the reinforced zone when appropriate granular soils are not available or expensive. Any malfunction of the drain system could then cause the development of the pore water pressure in the backfill and therefore, reduced the soil shear strength since the cohesive soil permeability is very low.

The water presence in the reinforced backfill is an important concern. Its effect depends from the water table level. It represents a serious risk on the internal stability of geosyntheticreinforced earth retaining walls. The use of sensors on the geosynthetic reinforcement can help monitoring and consequently preventing risks that can occur.

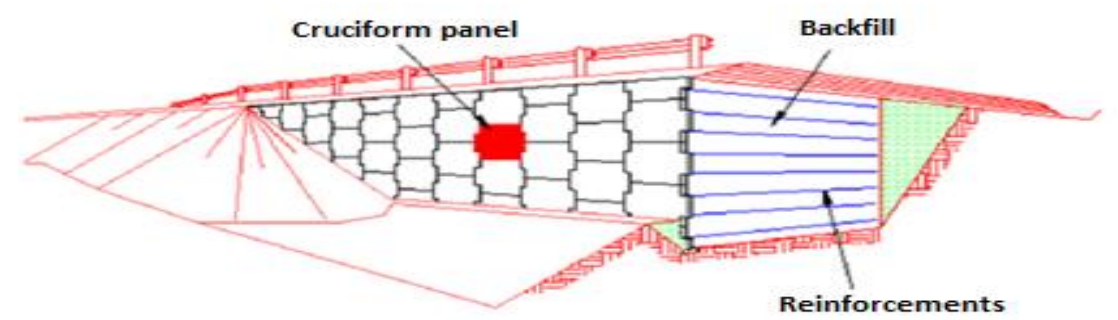

Figure 1: Reinforced earth retaining wall

\section{Sensor optimization}

\subsection{Internal forces monitoring sensors}

The installation of sensors on the geosynthetic reinforcement helps to monitor and measure the geosynthetic reinforcement internal forces. This leads to observe the evolution of the structure response and behavior, and prevent damages at early stage.

The internal stability of reinforced earth retaining walls is commonly investigated by using the limit equilibrium method. It is the most popular method due to its simplicity. However, it does not consider the stress-strain soil relations and it requires some assumptions. Limit analysis approach is an alternative methodology that considers the soil stress strain relation and permits to obtain rigorous upper or lower bound to the real solution through its 
two theorems. The upper bound theorem known also as the kinematic approach of limit analysis, is now widely used to investigate the internal stability of reinforced earth retaining walls. The form of failure surface is assumed in this kind of analysis. The failure surface is considered log-spiral in this study, based on the results and observations of previous works which indicate that it is the most critical failure mechanism.

In general, the reinforcement internal force varies along the geosynthetic element. The internal forces distribution is generally characterized by a maximum value at or near the intersection of the reinforcement with the critical failure surface. The reinforcement internal force or strain decreased gradually to both sides. It decreases to zero at the rear end (free end) and to the connection strength at the wall reinforcement connection.

To optimize the sensor locations in the reinforced zone in order to decrease their number, it is important to locate the regions where the critical surface could propagate. In unsaturated soil with variable water table level, the variation of the water table level may affect the anticipated failure surface location.

\subsection{Internal stability of reinforced earth retaining wall}

The kinematic theorem of limit analysis is based on the work rate balance between the external forces and the internal energy dissipation. It is used to find a lower bound to the reinforcement strength required to ensure the structure stability. The analysis here concerns reinforced earth walls where geosynthetic reinforcements are horizontal and uniformly distributed, have uniform length and their resistance to shear, bending and compression is ignored. Applicability of the theorem requires that the soil is described by an ideally rigid perfectly plastic behavior according to normality flow rule. The point-to-point method is used to generate the log-spiral failure mechanism. This technique has advantages over the conventional kinematic approach of limit analysis that it can be applied for non-homogeneous backfill. In addition, the pseudo-dynamic approach can be used to represent the seismic loading. However, the internal stability assessment is conducted here under static loading.

The generation of the failure mechanism is shown in Figure 2 where the block $A B D C$ rotates around the center of rotation $O$ with an angular velocity $\Omega$. The failure surface meets the velocity vector with an angle equal to the soil friction angle $\varphi^{\prime}$. The angle $\delta \theta$ defines the accuracy of the failure mechanism. The positive parameter $\xi$ defines the depth of the water table. When this parameter is equal to zero, the backfill is saturated. A value between 0 and 1 indicates that the backfill is divided in two zones, saturated and unsaturated. When this parameter exceeds 1 , the backfill is unsaturated. The steps of the generation process and the work rate calculations are described in [2] who investigate the seismic internal stability of geosynthetic-reinforced earth wall with the pseudo-static method. In addition, the same authors include the crack formation as a part of the failure mechanism in their analysis in another study [3] where also, the pseudo-dynamic method is implemented to consider the seismic loading. However, in both works, the presence of water is not considered in the analysis. Since this paper considers only the static loading, the external forces contain only the soil weight and the pore-water pressure work rates. The second occurs only in the saturated zone. On the other hand, the internal energy dissipation occurs along the velocity discontinuity and along the reinforcement by tensile or pullout failures. For unsaturated zone, the soil suction tends to increase the soil cohesion. Therefore, the effective cohesion $c^{\prime}$ is used in the calculation of internal energy dissipation in the saturated zone (along BD). The total cohesion, resulting by the summation of the effective cohesion to the apparent cohesion due to matric suction, is used in the unsaturated zone (along DC).

The effect of water presence in the saturated zone on the external work rate calculation and the expression of the total cohesion in the unsaturated zone are presented hereafter. 


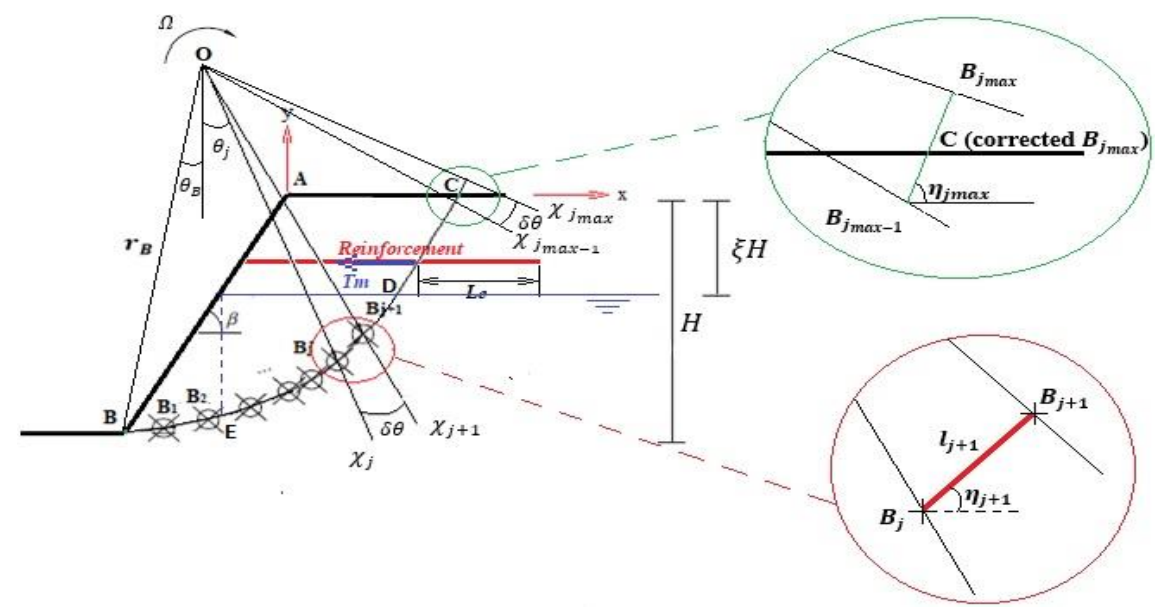

Figure 2: Failure mechanism generation process by the discretization method

In the saturated zone, the pore-pressure work rate considered as external force, is applied to the soil skeleton and the boundary. Since rigid block assumption is considered, the porepressure effect is limited at the boundary surface and it is calculated as follows:

$$
\dot{W}_{u}=-\int_{S_{B D}} u \cdot n_{i} \cdot v_{i} d S
$$

where $v_{i}$ the velocity vector in the collapse block, $S$ the boundary surface of the failure block respectively, $n_{i}$ the outward unit vector normal to the surface $S$. The pore water pressure is considered by using the pore-water pressure coefficient $r_{u}$ introduced in [4]. The pore-water pressure $u$ at a depth $h$ below the water-table level, is assumed to be equal to $r_{u} \gamma h$ where $\gamma$ is the soil unit weight. The work rate of the pore water pressure along the discontinuity surface is given in the discretization method as the summation of the elementary work rate as follows:

$$
\begin{cases}\dot{W}_{u}=\sum_{j} r_{u} \cdot \gamma \cdot\left(x_{j} \cdot \tan \beta-y_{j}\right) \cdot l_{j} \cdot \Omega \cdot L_{j} \cdot \sin \varphi^{\prime} & \text { along the boundary } B E \\ \dot{W}_{u}=\sum_{j} r_{u} \cdot \gamma \cdot\left(-y_{j}-\xi H\right) \cdot l_{j} \cdot \Omega \cdot L_{j} \cdot \sin \varphi^{\prime} & \text { along the boundary } E D\end{cases}
$$

where $l_{j}$ is the length of $\left[B_{j-1} B_{j}\right], L_{j}$ the length of $\left[O B_{j}\right]$ an $\left(x_{j}, y_{j}\right)$ the coordinates of $B_{j}$.

For unsaturated soil, the existence of the soil suction tends to increase the soil cohesion and consequently the shear strength. Several equations have been proposed to calculate the increase in the unsaturated shear strength $\tau_{f}$ with the matric suction $\left(u_{a}-u_{w}\right)$ with $u_{a}$ and $u_{w}$ being respectively, the pore air pressure and the pore water pressure. As proposed in [5], a linear equation for the unsaturated soil shear strength is considered. The linear increase of the shear strength was designated using the angle $\varphi^{b}$ that represents the rate of increase in shear strength relative to matric suction. This parameter had the character of a friction angle. Then, the unsaturated soil shear strength can be expressed as an extended Mohr-Coulomb shear strength equation :

$$
\tau_{f}=c^{\prime}+\left(\sigma_{n}-u_{a}\right) \tan \varphi^{\prime}+\left(u_{a}-u_{w}\right) \tan \varphi^{b}
$$


where $\left(\sigma_{n}-u_{a}\right)$ is the net normal stress on the failure plane.

Equating the external work rates and the internal energy dissipation provides the objective function to be maximized in order to calculate the reinforcement strength required to ensure the wall stability. The geometrical parameters $r_{B}$ and $\theta_{B}$ are considered in the optimization process, where $r_{B}$ is the length of $O B, \theta_{B}$ is the angle between the $y$ axis direction and the line $O B$ as shown in Figure 2.

\subsection{Results}

In order to investigate the effect of water-table level and variations of hydrological conditions of the backfill soil on the required reinforcement strength and on the location of the critical failure surface and consequently the locations of maximum internal forces, a numerical example is presented here. The reinforced earth retaining wall is described by the following parameters: $H=6 \mathrm{~m}, \beta=75^{\circ}, \gamma=19 \mathrm{kN} / \mathrm{m}^{3}, \varphi^{\prime}=25^{\circ}, c^{\prime}=8 \mathrm{kPa}, \delta \theta=0.01^{\circ}, L_{r}=0.75 \mathrm{H}$, $n_{r}=10$, where $H$ is the wall height, $\beta$ is the wall inclination, $L_{r}$ is the reinforcement length, $n_{r}$ is the reinforcement number uniformly distributed.
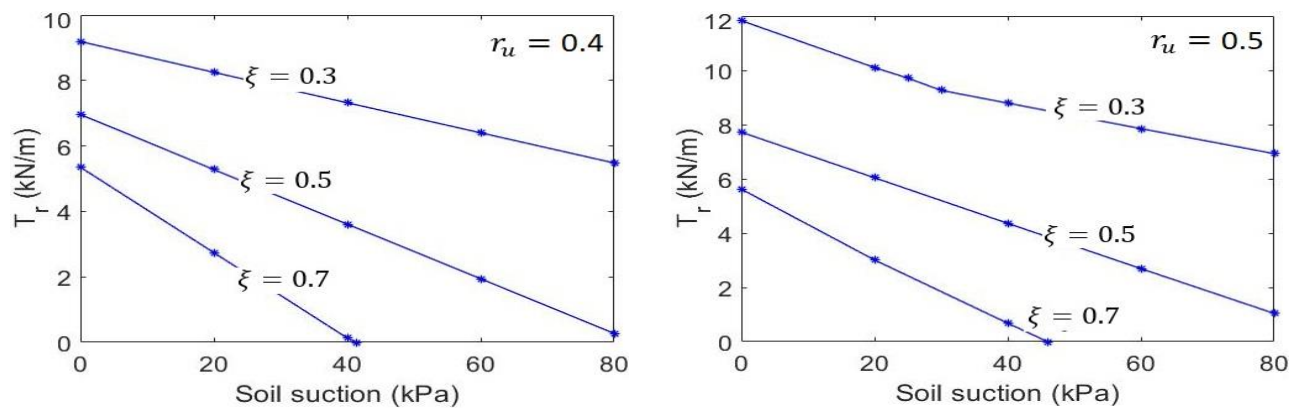

Figure 3: Required reinforcement strength for different value of soil suction

The results are illustrated in Figure 3. It is clear that the required reinforcement strength $T_{r}$ decreases linearly with the soil suction in the unsaturated zone. It increases when the water table depth decreases and when the pore-water pressure coefficient $r_{u}$ increases. The variation of the required reinforcement strength with the matric suction is linear except the case when the water table is at $1.8 \mathrm{~m}$ below the ground surface $(\xi=0.3)$ and the pore-water pressure coefficient $r_{u}=0.5$. The reason of non-linearity is that under these conditions and for a matric suction smaller than $30 \mathrm{kPa}$, the geosynthetic reinforcements in the upper layers fail in pullout contrary to the other cases where all the reinforcement layers fail in tensile rupture. The results show the importance of accurate measurement and prediction of the soil suction and the importance of considering the water table level variation that can occurs due to the rainfalls.

During the structure monitoring, the sensors used to measure the internal reinforcement force must be implemented near the critical surface and when the reinforcement force measured approaches the anticipated required reinforcement strength, the monitor engineer must react because the limit state is reached and failure will occur. However, the variation of the water table level may change the location of the critical failure surface. If all the reinforcement layers fail in rupture (Figure 4a), the location of the critical failure surface remains almost the same. However, if some reinforcement layers fail in pullout (Figure 4b), the critical failure surface tends to drift away from the wall facing and the required reinforcements strength to maintain the structure stability is greater than the case when all reinforcement layers fail in tension. Thus, the critical failure surface location is influenced 
by the water table level and the soil matric suction in the unsaturated zone. For an important soil matric suction, the critical failure surface remains almost in the same location with the variation of water table level. However, it changes for small matric suction values. For an accurate monitoring and safety concerns, the sensors locations must consider the possible variation in the water table level and consequently cover a wider region predetermined. An alternative efficient method for monitoring the structure is to use simultaneously sensors to detect the location of groundwater. Once it is determined, the region of interest where the internal reinforcement strength sensors need to get attention is specified.
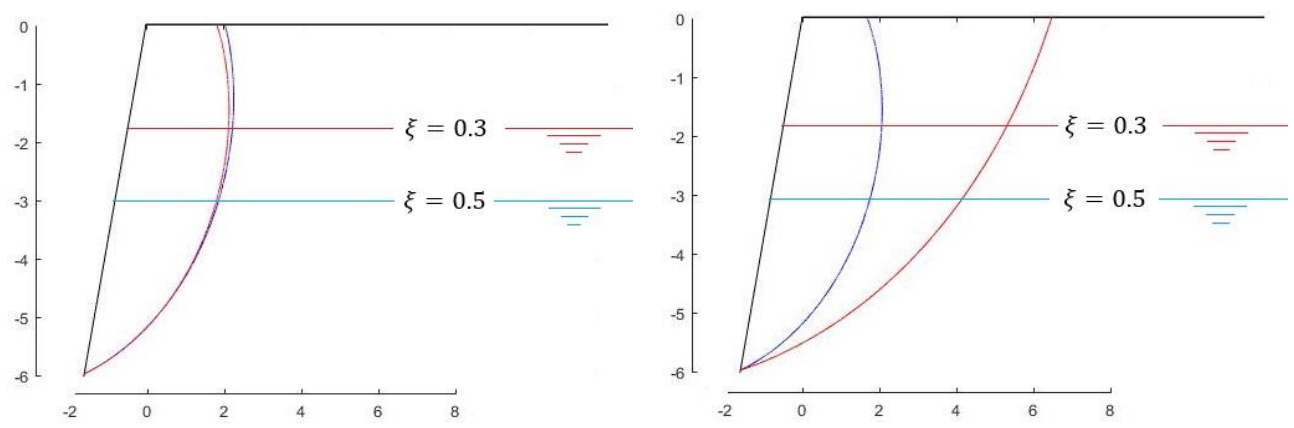

Figure 4: Critical failure surfaces for $r_{u}=0.5$ : (a) $u_{a}-u_{w}=60 \mathrm{kPa}$; (b) $u_{a}-u_{w}=20 \mathrm{kPa}$

\section{Conclusions}

This work adopted the upper bound theorem of limit analysis combined with the discretization method for the determination of the reinforcement strength required to ensure the stability of geosynthetic reinforced earth retaining walls. The effect of water with different water-table levels are considered.

The results show the effect of the water table level and the matric suction in the unsaturated zone on the required reinforcement strength. In addition, the variation of the water table has shown a great influence on the location of the critical failure surface where the maximum internal reinforcement strength will occur. This happens when the upper reinforcement layers fail in pullout due the water table approach from the ground surface. The monitoring sensors should be implemented over a wide zone on the reinforcement layers to consider the possible variation of the groundwater level and the region of interest where the internal reinforcement strength sensors need to get attention is specified based on the location of the groundwater.

\section{References}

1. R. M. Koerner, G. R. Koerner,. Geotext and Geomembranes, 46, 9 (2018).

2. H. Alhajj Chehade, D. Dias, M. Sadek, O. Jenck, F. Hage Chehade, Acta Geotech, (2019). (Under review).

3. H. Alhajj Chehade, D. Dias, M. Sadek, O. Jenck, F. Hage Chehade, Geotext Geomembranes, 47, 12 (2019).

4. A. W. Bishop, N. R. Morgenstern, Géotechnique, 10, 25 (1960).

5. D. G. Fredlund, N. R. Morgenstern, R. A. Widger, Can. Geotech. J., 15, 9 (1978). 